\title{
TRIBUNAL DE CONTAS DOS ESTADOS - MESA DA ASSEMBLÉIA \\ LEGISLATIVA - REGIME DE JULGAMENTO
}

Tribunal de Contas dos Estados. Competência. observância compulsória do modelo federal. Inconstitucionalidade de subtração ao Tribunal de Contas da competência do julgamento das contas da Mesa da Assembléia Legislativa - compreendidas na previsão do art. 7I, II, da Constituição Federal, para submetê-las ao regime do art. 71 , c/c. art. 49, IX, que é exclusivo da prestação de contas do Chefe do Poder Executivo.

I. $O$ art. 75, da Constituição Federal, ao incluir as normas federais relativas à "fiscalização" nas que se aplicariam aos Tribunais de Contas dos Estados, entre essas compreendeu as atinentes às competências institucionais do TCU, nas quais é clara a distinção entre a do art. $71, I-d e$ apreciar e emitir parecer prévio sobre as contas do Chefe do Poder Executivo, a serem julgadas pelo Legislativo - e a do art. 7I, II - de julgar as contas dos demais administradores e responsáveis, entre eles, os dos órgãos do Poder Legislativo e do Poder Judiciário. 
II. A diversidade entre as duas competências, além de manifesta, é tradicional, sempre restrita à competência do Poder Legislativo para o julgamento às contas gerais da responsabilidade do Chefe do Poder Executivo, precedidas de parecer prévio do Tribunal de Contas: cuida-se de sistema especial adstrito às contas do Chefe do Governo, que não as presta unicamente como chefe de um dos Poderes, mas como responsável geral pela execução orçamentária: tanto assim, que a aprovação política das contas presidenciais não libera do julgamento de suas contas específicas os responsáveis diretos pela gestão financeira das inúmeras unidades orçamentárias do próprio Poder Executivo, entregue a decisão definitiva ao Tribunal de Contas.

\section{SUPREMO TRIBUNAL FEDERAL Ação Direta de Inconstitucionalidade no 848}

Requerente: Procurador Geral da República

Requerido: Assembléia Legislativa do Estado de Mato Grosso Relator: Sr. Ministro SEPÚLVEDA PERTENCE

\section{ACÓRDĀO}

Vistos, relatados e discutidos estes autos, acordam os Ministros do Supremo Federal, em sessão plenária, na conformidade da ata do julgamento e das notas taquigráficas, por maioria de votos, em julgar procedente a ação direta e, em consequiência, declarar a inconstitucionalidade da Emenda Constitucional $\mathrm{n}^{\mathbf{2}}$ 1, de 10/12/1991, do Estado de Mato Grosso. Brasília, 11 de fevereiro de 1999.

CELSO MELLO - PRESIDENTE SEPÚLVEDA PERTENCE - RELATOR

\section{RELATÓRIO}

\section{O SENHOR MINISTRO SEPÚLVEDA} PERTENCE - Este o núcleo da petição inicial desta ação direta, da lavra do ProcuradorGeral da República, o il. Dr. Aristides Junqueira:

"É este o teor do diploma legal impugnado:

“Art. 19. O inciso I do artigo 47 da Constituição Estadual passa a ter a seguinte redaçāo: Art. 47.
I. apreciar as contas prestadas anualmente pelo Governador do Estado, e pela Mesa da Assembléia Legislativa, mediante parecer prévio a ser elaborado em sessenta dias a contar do seu recebimento e enviado à Assembléia Legislativa para julgamento.

Art. 22. Esta Emenda Constitucional entra em vigor na data de sua promulgagão."

A redação original do art. $47 \mathrm{e}$ inciso 1 , da Constituição do Mato Grosso, objeto, este último, da Emenda acima transcrita, é a seguinte:

"Art. 47. O controle externo, a cargo da Assembléia Legislativa, é exercido com o auxílio do Tribunal de Contas do Estado, ao qual compete:

I. apreciar as contas prestadas, anualmente, pelo Governador do Estado, mediante parecer prévio a ser elaborado em sessenta dias, a contar de seu recebimento e enviado à Assembléia Legislativa para julgamento."

A presente iniciativa atende à solicitaçāo do Tribunal de Contas do Estado do Mato Grosso, constante do expediente anexo, onde se aponta a incompatibilidade das disposições transcritas com os incisos I e II do art. 7 da Constituição Federal. 
As contas da Mesa da Assembléia Legislativa estão sujeitas a julgamento do Tribunal de Contas do Estado, por força do disposto no inciso II do art. 71, combinado com o art. 75 da Constituição Federal, e não simplesmente a parecer prévio de Corte de Contas, como previsto no inciso I do mesmo artigo, dispositivo este aplicável apenas às contas prestadas anualmente pelo Presidente da República."

Requerida a suspensão cautelar da emenda questionada, deferiu-a o Plenário, vencido o em. Ministro Marco Aurélio, em 1.7.93, relator o em. Ministro Celso de Mello (Lex 187/124).

Prestou informações a Assembléia Legislativa do Mato Grosso, para contestar a inconstitucionalidade alegada.

Depois de dar conta da regularidade formal do processo legislativo da emenda constitucional impugnada, no mérito, a partir do art. 75 e parágrafo único da Constituição Federal, aduzem as informações (f. 24, 28):

"A subordinação normativa e explícita, consubstanciada neste artigo - é somente quanto à limitação do número de Conselheiros, conforme determinado no Parágrafo único. Pois, quanto ao "caput" deste artigo, é importante analisar a expressão - " no que couber” - sob a ótica do permissível.

Ainda aqui, no uso dos facultativos expressos no $\S 1^{\mathfrak{Q}}$ do Art. 25, esta Casa de Leis respeitou, também, "os princípios" configurados no "caput" do referido artigo constitucional citado.

Inaceitável, na interpretação fria da análise procedida pelo douto e respeitável Relator, que se atribua à Mesa da Assembléia Legislativa do Estado de Mato Grosso, dado o conteúdo da Emenda Constitucional ne 01/91, o objetivo menos digno, ainda quando endereçado à esta Casa de Leis, aquele de fugir à fiscalização do Tribunal de Contas, conforme se assevera à fls. 6 , item 4, assim expresso:

"Depois, de qualquer ângulo que se examina a matéria, ver-se-á que a Mesa da Assembléia Legislativa do Estado de Mato Grosso busca pôr-se à margem da açāo fiscalizadora do Tribunal de Contas..."

Ali estão. pois, à mostra e eloqüente evi- dência, nos textos constitucionais, o respeito, a valoração, a atribuição e competência que as Constituições Federal e Estadual infundem às Colendas Cortes de Contas quando se lhe destina o papel relevante de órgão auxiliar para o controle externo, responsabilidade esta da Assembléia Legislativa.

Cristalinamente, ali se definem no "caput" do Art. 70 e "caput" do Art. 46 da Constituiçāo Federal e Estadual que _- "o controle externo será exercido pelo congresso e por similitude, pela Assembléia Legislativa. Reiterado no "caput" do Art. 71 e "caput" do Art. 47 das citadas Constituiçōes que - "o controle externo, a cargo do Congresso, aqui da Assembléia Legislativa, será exercido com o auxílio do Tribunal de Contas."

Pressurosa, senão mesmo laborada em inescondível equívoco, a suposição de que a Mesa Diretora da Assembléia Legislativa de Mato Grosso, nāo esteja inclusa nas regras gerais “da fiscalização contábil, financeira e orçamentária” estatuídos nas Constituiçōes, em especial destaque, a de "prestar contas", conforme previsto nos parágrafos únicos, do Art. 70 da Constituição Federal e Art. 46 da Constituição Estadual.

Ressalva-se, que a Emenda constitucional em tela, apenas indica claramente que as contas desta Casa de Leis, são submetidas à apreciação do Tribunal de Contas.

Mais do que isso, ao Tribunal de Contas é conferida a livre iniciativa, exponte própria, de "realizar, inspeções e auditorias, de natureza contábil, financeira, orçamentária, operacional e patrimonial, em quaisquer unidades administrativas dos Poderes Legislativo, ..." (Art. 47 - inciso IV da Constituição Estadual).

Nítido como a claridade da Justiça, que a Emenda em julgamento não afeta a atribuição constitucional do Tribunal de Contas e nem constitui conflito entre o mesmo e este Poder Legislativo."

Subscreveu essas razões o il. AdvogadoGeral da Uniāo para defender a norma atacada.

Finalmente, o parecer da Procuradoria-Geral da República de autoria do il. Subprocu- 
rador-Geral Flávio Giron, é pelo acolhimento da argüiçāo (f. 70, 75):

“...se a Constituição Federal dispõe que a Tribunal de Contas da União compete 'apreciar as contas prestadas anualmente pelo Presidente da República mediante parecer prévio...' (inciso I), e 'julgar a. contas dos administradores e demais responsáveis por dinheiros, bens e valores públicos da administração direta e indireta, ...' (inciso II), quis excluir do julgamento pelo Tribunal de Contas apenas o Presidente da República, e, em decorrência, aos Governadores, nos Estados (artigo 75).

Ao legislador constituinte estadual é defesa a disposição de normas que diferem dos moldes estabelecidos na Carta Federal, sob pena de ultrapassar o poder que lhes é conferido em decorrência do originário. Assim sendo, merece procedência a ação, merecendo ser confirmada a medida liminar."

É o relatório, cuja cópia se remeterá aos ilustres Ministros.

\section{VOTO}

O SENHOR MINISTRO SEPÚLVEDA PERTENCE - (Relator): No d. voto condutor do acórdão que deferiu a cautelar, acentuou o em. Ministro Celso de Mello (f. 48):

"Os Estados-membros estão sujeitos, em matéria de organização, composição e atribuiçōes fiscalizadoras dos seus Tribunais de Contas, ao modelo jurídico estabelecido pela Constituição da República. Essa subordinação normativa ao padrão federal deriva de cláusula explícita consubstanciada no art. 75 , caput, da Carta Política, que assim dispōe, verbis:

"As normas estabelecidas nesta seção aplicam-se, no que couber, à organização, composição e fiscalização dos Tribunais de Contas dos Estados (...)."

O Supremo Tribunal Federal, tendo presente essa realidade jurídico-normativa, já proclamou, na análise das funções institucionais cometidas a esse importante órgão estatal de controle externo, que

$$
\text { " (...) }
$$

O regramento dos Tribunais de Contas estaduais, a partir da Constituição de 1988 inobstante a existência de domínio residual para sua autônoma formulaçāo - é matéria cujo relevo decorre da nova fisionomia assumida pela Federação brasileira e, também, do necessário confronto dessa mesma realidade jurídico-institucional com a jurisprudência do Supremo Tribunal Federal, que, construída ao longo do regime constitucional precedente, proclamava a inteira submissão dos Estadosmembros, no delineamento do seu sistema de controle externo, ao modelo jurídico plasmado na Carta da República.

(RTJ 132/1034, rel. Min. CELSO DE MELLO)

A Constituiçāo Federal, ao dispor sobre o controle externo das contas anualmente prestadas pelo Chefe do Poder Executivo, prescreve que estas, uma vez apreciadas pelo Tribunal de Contas (art. 71, I), deverão ser julgadas pelo Poder Legislativo (art. 49, IX).

A apreciação das contas anuais da Chefia do Executivo constitui uma das mais elevadas atribuições do Tribunal de Contas, a quem compete examiná-las de forma global, mediante parecer prévio, no que concerne aos seus aspectos de legalidade, legitimidade e economicidade.

A análise do art. 71, I, da Carta Federal extensível aos Estados-membros por força do art. 75 - permite, de logo, extrair duas conclusões: (1) a de que o Tribunal de contas, somente na hipótese específica de exame das contas anuais do Chefe do Executivo, emite pronunciamento técnico, sem conteúdo deliberativo, consubstanciado em parecer prévio, destinado a subsidiar o exercício das atribuições fiscalizadoras do Poder Legislativo e (2) e a de que essa manifestação meramente opinativa não vincula a instituição parlamentar quanto ao desempenho de sua competência decisória.

Torna-se evidente, portanto, que, em se tratando das contas anuais do Chefe do Poder Executivo - $e$ destas somente - as funçōes do Tribunal de Contas assumem o caráter de mero pronunciamento opinativo.

Cuidando-se, porém, das contas dos demais 
administradores e responsáveis por dinheiro, bens e valores públicos - quaisquer que sejam as unidades administrativas e os Poderes do Estado a que se vinculem - caberá ao Tribunal de Contas desempenhar função jurídica revestida de um maior relevo, que consiste no exercício de típica atribuição deliberativa.

$\mathrm{O}$ art. 71, II, da Carta Política, que se impōe, por norma de extensão (art. 75), à observância compulsória dos Estados-membros, confere ao Tribunal de Contas a prerrogativa de $j u l$ gar, ainda que em sede administrativa, as contas prestadas pela Mesa Diretora do Órgão Legislativo, inclusive.

Dai o autorizado magistério de HELY LOPES MEIRELLES ("Direito Administrativo Brasileiro", p. 602, $17^{\mathrm{a}}$ ed., 1992, Malheiros Editores) que, após destacar a significativa ampliação das atribuições institucionais dos Tribunais de Contas, asseverou que o poder de controle externo por eles exercido expressa-se, fundamentalmente, em funções de caráter técnico-opinativo e, também, de natureza jurisdicional-administrativa.

Nesse contexto - assinala o saudoso publicista - compete ao Tribunal de Contas, com base no art. 71, II, da Carta Federal, proceder ao julgamento das contas, dentre outros, dos administradores e demais gestores que, vinculados aos Poderes Legislativo e Judiciário, sejam responsáveis por dinheiro, bens e valores públicos.

A norma ora impugnada, ao dispensar às contas anuais prestadas pela Mesa da Assembléia Legislativa o mesmo regime jurídico peculiar às contas do Chefe do Poder Executivo, também atribuindo ao pronunciamento do Tribunal de Contas, no que concerne ao órgão parlamentar, função meramente opinativa, parece ter infringido a regra de competência inscrita no art. 71, II, da Carta Política, que investe essa Corte no poder de julgar as contas, mesmo quando apresentadas pela própria instituição legislativa".

Posto emitidas a título de deliberação do fumus boni juris bastante à decisāo cautelar, essas considerações bastam, ao meu ver, para lastrear agora o julgamento definitivo no mesmo sentido.
Não as abalou a defesa das informações: independentemente de saber se cuida ou não de princípios constitucionais impostos à observância dos constituintes estaduais, conforme a norma geral do art. 25 , o art. 75 da Constituição contém preceito específico de aplicação aos Estados-membros, sempre que couber, das normas relativas ao Tribunal de Contas da União, "à organização, composifâa e fiscalização aos Tribunais de Contas dos Estados e do Distrito Federal, bem como dos Tribunais e Conselhos e Contas dos Municípios".

Não procede a frágil alegação de reduzir-se o alcance dessa norma de extensão "à limitação do número de Conselheiros, conforme determinado no parágrafo único": ao contrário, este, o parágrafo único do art. $75, \mathrm{CF}$, se afasta do modelo federal imposto no caput, ao dispor que os conselheiros dos Tribunais de Contas locais serão apenas sete, e não nove, como ocorre no da União.

Desse modo, ao invés de delimitar o âmbito normativo do caput do art. $75, \mathrm{CF}$, o seu parágrafo constitui exceção ao que nele se preceitua.

De resto, no contexto do caput do mesmo art. 75, CF, a inclusão das normas federais relativas à "fiscalização" nas que se aplicariam aos Tribunais de Contas dos Estados, entre essas compreendeu as atinentes às competências institucionais do TCU, nas quais é clara a distinção entre a do art. 71, I- de apreciar e emitir parecer prévio sobre as contas do chefe do Poder Executivo, a serem julgadas pelo Legislativo - e a do art. 71, II - de julgar as contas dos demais administradores e responsáveis.

A diversidade entre as duas competências, além de manifesta, é tradicional, sempre restrita a competência do Poder Legislativo para o julgamento às contas gerais da responsabilidade do Chefe do Poder Executivo, precedidas de parecer prévio do Tribunal de Contas: cuida-se de sistema especial adstrito às contas do Chefe do Governo, que não as presta unicamente como chefe de um dos Poderes, mas como responsável geral pela execução orçamentária: tanto assim que a aprovação política das contas presidenciais não libera do 
julgamento de suas contas específicas os responsáveis diretos pela gestão financeira das inúmeras unidades orçamentárias do próprio Poder Executivo, entregue a decisão definitiva ao Tribunal de Contas.

Por isso - data venia do raciocínio desenvolvido - julgamento liminar no voto vencido do em. Ministro Marco Aurélio, é que não cabe transplantar para a prestação de contas da administração financeira dos demais Poderes o que a Constituição restringiu às do Chefe do Poder Executivo.

Anoto que, em casos similares, nessa linha o Tribunal tem seguidamente decidido, posto que em sede cautelar (ADIn MC 1440-RO, 19.12.94, Celso; ADIn MC 1779-PE, 23.4.98, Galvão, Inf. STF 107): note-se que, na ADIn MC 1440, cit., assim como na ADIn MC 1175 19.12.94, a divergência parcial dos ems. Ministros Marco Aurélio e Celso de Mello, assim como a minha própria, cingiu-se às contas do próprio Tribunal de Contas, em relação às quais nos pareceu razoável, à primeira vista, a construção que transfere para órgão diverso, o do Poder Legislativo, a competência para julgá-las. É questão que não está em causa.

Certo, no que toca particularmente às contas da administração das casas parlamentares sói afirmar-se a impossibilidade de confiar-se o seu julgamento ao Tribunal de Contas a partir da caracterização deste como órgão auxiliar do Poder legislativo: é aforismo, contudo salvo no processo de tomada das contas gerais do Presidente da República, que lhe deu origem - que hoje, à vista da Constituição, tem mais tradição do que validade dogmática.

Julgo, assim, procedente a ação e declaro inconstitucional a Emenda Constitucional $n^{2}$ 1, de 10.12.91, à Constituição do Estado de Mato Grosso: é o meu voto.

\section{VOTO}

O SENHOR MINISTRO MARCO AURÉLIO - Senhor Presidente, rememoro o teor do dispositivo a partir da redação originária que lhe foi dada pelos Constituintes estaduais.
De acordo com o artigo 47, inciso I, da Constituição do Mato Grosso:

Art. 47. O controle externo, a cargo da Assembléia Legislativa; é exercido com o auxílio do Tribunal de Contas do Estado, ao qual compete:

I - apreciar as contas prestadas, anualmente, pelo Governador do Estado, mediante parecer prévio a ser elaborado em sessenta dias a contar de seu recebimento e enviado à Assembléia Legislativa para julgamento.

Foi editada a emenda, e o preceito que interessa, que está em análise, passou a ter a seguinte redação.

Art. 47. (..)

I - apreciar as contas prestadas, anualmente, pelo Governador do Estado, e pela Mesa da Assembléia Legislativa, mediante parecer prévio a ser elaborado em sessenta dias a contar do seu recebimento e enviado à Assembléia Legislativa para julgamento.

O que ocorreu, então? Explicitou-se que também em relação às contas da Assembléia, tal como vinha ocorrendo no tocante às contas do Chefe do Poder Executivo, a atuação do Tribunal de Contas seria simplesmente opinativa, ou seja, emitiria, quanto a essas contas do Poder Legislativo local, um parecer, não as julgando.

Senhor Presidente, quando apreciado o pedido de concessão de medida acauteladora, ousei externar convencimento preliminar a respeito do tema diverso do que foi sustentado posteriormente, com o endosso dos demais integrantes da Corte, por V. Exa., e aí fiz ver: "Senhor Presidente, a novidade que temos é a inclusão da Mesa da Assembléia e o tratamento que é deferido pertinente ao Chefe do Poder Executivo."

Nesse exame preliminar, entendo que o preceito nāo conflita, em si, com o inciso I do artigo 71 da Constituição, porquanto, de acordo com esse dispositivo, compete ao Tribunal de Contas apreciar as contas prestadas, anualmente, pelo Presidente da República, emitindo, apenas, o parecer.

O que se verifica, aí, é a potencializaçāo do 
fato de as contas estarem sendo prestadas por um Chefe de Poder, por um Poder.

Ora, no caso, a Casa Legislativa é administrada pela Mesa, mas nem por isso podemos concluir que tem pertinência a hipótese do inciso II do artigo 71; no que dispõe que, em se tratando de contas prestadas por administradores-gênero, o Tribunal procede ao julgamento e não à simples emissão de parecer.

Não creio que possamos chegar ao ponto de colocar em primeiro plano o que se contém, explicitamente, no inciso II. Para mim, pelo menos neste exame inicial, transparece que não cabe emprestar tratamento diferenciado conforme a origem das contas. Se a origem for do Chefe do Poder Executivo, o Tribunal de Contas emite apenas parecer, mas, se as contas sāo prestadas pelo Poder Legislativo, ele as julga. Quer dizer, o órgāo auxiliar, que é a Corte de Contas, passa a julgar as contas do Poder a quem ele auxilia!!

Senhor Presidente, penso serem inconciliáveis as colocaçōes: a existência do Tribunal de Contas como órgão auxiliar do Poder Legislativo, o controle que é atribuído pela Carta da República - e aí temos o órgão máximo desse controle, que é o próprio Poder Legislativo - e a possibilidade de o órgão auxiliar vir, no campo administrativo, a julgar as contas do próprio órgão a que auxilia.

Fico a imaginar, por exemplo, a aplicação, pelo Tribunal de Contas do Estado, à Assembléia Legislativa, no caso de ilegalidade de despesa ou irregularidade de contas, das sanções previstas em lei, conforme disposto no inciso VIII do artigo 71, e também a imposição de prazo à Assembléia para que adote certas providências.

Em síntese, não vejo como inverter a ordem natural das coisas; não vejo como atribuir a um órgão auxiliar papel de relevância substancial, como é o papel de julgar as contas do próprio Poder a que auxilia.

Por isso, entendo que não houve, na aprovação da emenda constitucional que alterou a Carta Estadual, transgressão ao que se contém no artigo 71 , inciso I, da Constituição Federal, preceito que revela, no caso, competir ao Tribunal de Contas da Uniāo, emitir parecer, também em sessenta dias (o prazo também está contido na Norma Maior Federal) sobre as contas do Presidente.

Em síntese, esse preceito não deságua na convicção de que, em relaçāo às contas do próprio Poder Legislativo, tem-se a incidência da regra do inciso II, que confere ao Tribunal de Contas o poder de julgá-las.

Peço vênia para, no caso, julgar improcedente o pedido formulado na inicial desta ação direta de inconstitucionalidade.

É o meu voto.

\section{O EXTRATO DE ATA}

AÇÃO DIRETA DE INCONSTITUCIONALIDADE N2 849-8

PROCED.: MATO GROSSO

RELATOR: MIN. SEPÚLVEDA PERTENCE

REQTE.: PROCURADOR-GERAL DA REPÚBLICA

REQDO:: ASSEMBLÉIA LEGISLATIVA DO ESTADO DE MATO GROSSO

Decisão: O Tribunal, por votação majoritária, julgou procedente a ação direta $\mathrm{e}$, em consequiência, declarou a inconstitucionalidade da Emenda Constitucional $\mathrm{n}^{2} 01$, de 10/12/1991, do Estado de Mato Grosso, vencido o Ministro Marco Aurélio, que a julgava improcedente. Votou o Presidente. Ausente, justificadamente, o Ministro Ilmar Galvão. Plenário, 11.02.99.

Presidência do Senhor Ministro Celso de Mello. Presentes à sessão os Senhores Ministros Moreira Alves, Néri da Silveira, Sydney Sanches, Octávio Gallotti, Sepúlveda Pertence, Carlos Velloso, Marco Aurélio, Maurício Corrêa e Nelson Jobim.

Procurador-Geral da República, Dr. Geraldo Brindeiro.

Luiz Tomimatsu, Coordenador 